University of Wollongong

Research Online

Coal Operators' Conference

Faculty of Engineering and Information

Sciences

2012

\title{
Application of a transversely isotropic brittle rock mass model in roof support design
}

David A. F. Oliveira

University of Wollongong, doliveir@uow.edu.au

Follow this and additional works at: https://ro.uow.edu.au/coal

\section{Recommended Citation}

David A. F. Oliveira, Application of a transversely isotropic brittle rock mass model in roof support design, in Naj Aziz and Bob Kininmonth (eds.), Proceedings of the 2012 Coal Operators' Conference, Mining Engineering, University of Wollongong, 18-20 February 2019

https://ro.uow.edu.au/coal/386

Research Online is the open access institutional repository for the University of Wollongong. For further information contact the UOW Library: research-pubs@uow.edu.au 


\title{
APPLICATION OF A TRANSVERSELY ISOTROPIC BRITTLE ROCK MASS MODEL IN ROOF SUPPORT DESIGN
}

\section{David Oliveira}

\begin{abstract}
Accurate modelling of the potential failure modes in the rock mass is an essential task towards a robust design of roof support systems in coal mines. The use of generalised rock mass properties based on averaged properties (e.g. Hoek-Brown model) has been found to limit the capability to reproduce the actual rock mass behaviour which may include a wide range of interacting and complex failure mechanisms such as shear and tension fracturing of the intact rock and shear and separation of pre-existing discontinuities, including re-activation. Recent studies have also shown that traditional models, such as the Mohr-Coulomb, may not accurately describe the behaviour of the intact rock, particularly for stress induced failures where spalling and slabbing are observed. This is mainly due to the cohesion and friction components of the shear strength of the intact rock not being mobilised at the same rate with strain-softening of the former component playing an essential role in the post peak behaviour. In addition, coal measure rocks are often transversely isotropic, both by way of the preferred orientation of clay particles within the finer grained lithology and by bedding textures and bedding partings, and this is often ignored in computer simulations. A newly developed transversely isotropic brittle rock mass model is applied in the simulation of a hypothetical and simple roadway development. A Cohesion Weakening - Friction Strengthening (CWFS) approach is adopted to describe the intact rock where the mobilisation and strain-softening of the two shear strength components are linked to plastic deformation. Failure and plastic deformations are also allowed to develop along any number of ubiquitous joint sets using a conventional Mohr-Coulomb failure criterion and applying the stress-strain correction accordingly. The impacts of anisotropy and brittle rock on the development of the excavation disturbed zone or height of softening, as often referred to, are investigated and their implication in the roof support design discussed.
\end{abstract}

\section{INTRODUCTION}

According to Seedsman (2011), most coal roof support design is either precedent/practice or empirically based using a rock mass classification scheme. Although a relatively dense bolting pattern is typically installed at the face often supplemented by longer reinforcement elements, such as cable bolts, there are still notable roof failures which, in addition to the evident impacts on safety, also result in the longwall face being stood for in excess of several weeks. Seedsman (2011) also states that at the consistent mining rates required, the reactionary/remedial components of the observational method are not appropriate and there is a need for robust estimates of likely roof support densities early in the planning stage, as well as in operations.

Detailed monitoring studies conducted in coal mines in a number of countries have shown that the failure mechanisms can be highly complex, involving fracture of rock, failure of bedding or joints, buckling of parted rock, and slip along weak surfaces (Gale, et al., 1992; Gale and Tarrant, 1997; Mark, et al., 2000). In such a complex scenario, computer simulations seem to provide more realistic results when a detailed geotechnical characterisation of the strata and stress field is available, and the many potential failure mechanisms involved are considered.

For example, Strata Control Technology (SCT) has reported successful modelling with a relatively comprehensive rock model at a wide variety of mine sites (Gale, et al., 1997; Sandford, 1998; Kelly, et al., 1998). Their model is similar to the Strain-softening Ubiquitous Joint Model (SUBI) included in the finite difference codes FLAC and FLAC3D where rock failure is based on Mohr-Coulomb criteria relevant to the confining conditions within the ground. A range of potential failure modes are simulated including:

- Shear fracture of intact rock;

- Tension fracture of the rock;

Senior Associate - Rock Mechanics Team Leader, Coffey Geotechnics, Lane Cove West, NSW 2066, dafo407@gmail.com T:0431441882 
- Bedding plane shear; and,

- Tension fracture of bedding (bedding separation).

In the SCT model, as well as the SUBI model, the intact rock matrix exhibits strain-softening post-failure behaviour with cohesion, friction angle, dilation angle and tensile strength specified as functions of the "plastic strain". A weakness plane of any orientation is also included in the SCT model, and this weakness plane may exhibit strain-softening behaviour. Due to this limitation, only bedding planes are modelled as it is the dominant weakness plane in coal measure rocks. However, rock masses in coal measures will typically have two other joint sets aligned orthogonally such that a valid model is a rock mass of cubes with dimensions from centimetres to metres (Seedsman, 2011).

In addition, coal measure rocks are transversely isotropic, both by way of the preferred orientation of clay particles within the finer grained lithology and by bedding textures and bedding partings, which according to Seedsman (2011) could only be modelled in a continuum assumption by invoking a transversely isotropic elastic model at the cost of only being able to conduct elastic analysis.

A new rock model has been developed at Coffey Geotechnics (Coffey) in order to address the above limitations. In addition, modelling of brittle behaviour of the intact rock by means of a Cohesion Weakening - Friction Strengthening (CWFS) approach and its effect on the development of the roof softening (fractured) zone are also discussed.

\section{EXTENDED SUBIQUITOUS ROCK MODEL}

The Extended Subiquitous (ESUBI) rock model was developed using subroutines in FLAC3D code and is in principle similar to the SCT and the Itasca SUBI models, thus, modelling the same range of potential failure modes. However, the model has been extended to include the following features:

- Unlimited number of ubiquitous joint sets given with any dip and dip direction angles;

- Transverse Isotropy with two different elastic moduli given: $E_{1}$, parallel to the plane of isotropy and $E_{3}$ perpendicular to this plane which is specified by a dip angle and a dip direction angle;

- Different elastic moduli for loading and unloading-reloading paths which is a behaviour typically observed in the field, particularly due to the highly non-linear effects of existing rock defects. As a result, total of four elastic moduli are given: two for loading and two for unloading-reloading.

The ESUBI rock model also accounts for both intact rock matrix and joint strain-softening/hardening post-failure behaviour where cohesion, friction angle, dilation angle and tensile strength are specified as functions of the appropriate "plastic strain". However, even when using strain-softening/hardening functions the conventional modelling approach is to implicitly assume that the cohesive and the normal stress-dependent frictional strength components are mobilised simultaneously, i.e., they are assumed to be additive before yielding of the rock.

Recent studies have shown that models based on the simultaneous mobilisation of cohesive and frictional strength components have not been successful in predicting the extent and depth of brittle failure. Hajiabdolmajid et al. (2002) have presented an approach where only the cohesional strength component is mobilised up to a stress level corresponding to the onset of micro-cracking. Beyond this stress level, there is a degradation of cohesion, i.e. softening, and mobilisation of the frictional strength component, which takes place due to the development of micro fractures. This CWFS mechanism is depicted in Figure 1. In this figure $\varepsilon_{c}^{p}$ marks the plastic shear strain beyond which there is only a residual cohesion and $\varepsilon_{f}{ }^{p}$ marks the plastic shear strain at which the frictional component is fully mobilised.

\section{Hypothetical triaxial tests on jointed rock samples}

Hypothetical triaxial tests on "virtual" rock mass samples are simulated in FLAC3D in order to demonstrate the capability of the ESUBI rock model with a CWFS approach as discussed above. Although, the ESUBI model allows for an unlimited number of joint sets, only one joint set (i.e. a bedding plane) was modelled for simplicity and clarity of the results, which could then be compared to simple analytical assessment for validation of the results. The adopted parameters are presented in Table 1 in which Poisson's ratio equal to 0.25 has been adopted. Upon tensile failure, the residual tensile 
strength is instantaneously set to zero. Unloading-reloading moduli have been assumed equal to the loading moduli. Dilation angles have been assumed zero although dilative behaviour would be expected for coal measure rocks and rock defects.
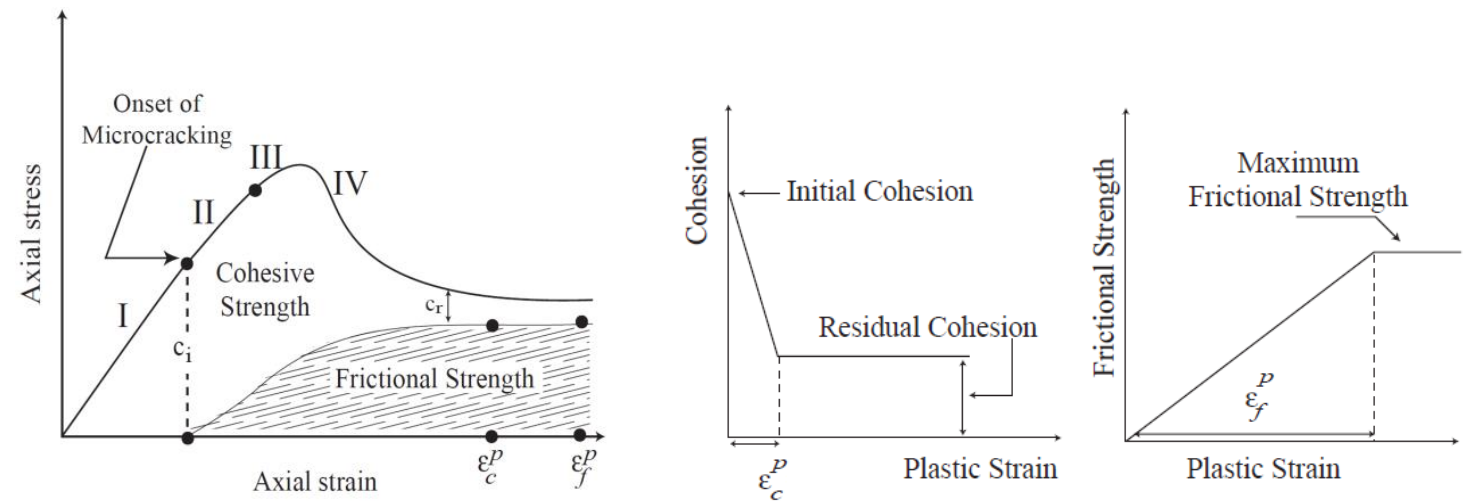

Figure 1 - Mobilisation of the strength components - cohesion and friction - in the CWFS model (after Hajiabdolmajid, et al., 2002)

Table 1 - Rock and joint parameters adopted

\begin{tabular}{|c|c|c|c|c|c|c|c|c|c|c|c|c|c|}
\hline \multicolumn{1}{|c|}{ Rock mass } & \multicolumn{9}{|c|}{ Intact rock } & \multicolumn{4}{c|}{ Bedding plane } \\
\hline $\begin{array}{c}E_{1} \\
(\mathrm{GPa})\end{array}$ & $\begin{array}{c}E_{3} \\
(\mathrm{GPa})\end{array}$ & $\begin{array}{c}\sigma_{\mathrm{ci}} \\
(\mathrm{MPa})\end{array}$ & $\begin{array}{c}\sigma_{\mathrm{ti}} \\
(\mathrm{MPa})\end{array}$ & $\begin{array}{c}\phi_{\mathrm{mp}} \\
\left(^{\circ}\right)\end{array}$ & $\begin{array}{c}\mathrm{C}_{\mathrm{pi}} \\
(\mathrm{MPa})\end{array}$ & $\begin{array}{c}\mathrm{C}_{\mathrm{ri}} \\
(\mathrm{MPa})\end{array}$ & $\begin{array}{c}\varepsilon_{c i}{ }^{p} \\
(\%)\end{array}$ & $\begin{array}{c}\varepsilon_{\mathrm{fi}^{p}} \\
(\%)\end{array}$ & $\begin{array}{c}\phi_{\mathrm{pj}} \\
\left(^{\circ}\right)\end{array}$ & $\begin{array}{c}\mathrm{C}_{\mathrm{pj}} \\
(\mathrm{MPa})\end{array}$ & $\begin{array}{c}\mathrm{C}_{\mathrm{rj}} \\
(\mathrm{MPa})\end{array}$ & $\begin{array}{c}\sigma_{\mathrm{tj}} \\
(\mathrm{MPa})\end{array}$ & $\begin{array}{c}\varepsilon_{c_{j}}{ }^{2} \\
(\%)\end{array}$ \\
\hline 10 & 2.86 & 16 & 1.8 & 40 & 6.44 & 0.3 & 0.23 & 0.1 & 35 & 1 & 0.1 & 0.38 & 1.2 \\
\hline
\end{tabular}

where $E_{1}$ and $E_{3}$ are the horizontal and vertical Young's moduli of the rock mass respectively when the joint dip angle is equal to zero (i.e. it rotates according to the specified joint angle); $\sigma_{c i}$ and $\sigma_{\mathrm{ti}}$ are the Uniaxial Compressive Strength (UCS) and tensile strength of the rock matrix respectively; $\phi_{\mathrm{pi}}$ is the peak friction angle of the rock matrix mobilised at a plastic shear strain $\varepsilon_{f i}{ }^{p} ; \mathrm{c}_{\mathrm{pi}}$ is the peak cohesion of the rock matrix assumed half of the stress at which unstable cracking starts to occur (approximately $80 \%$ of the UCS); $c_{r i}$ is the residual cohesion of the rock matrix mobilised at a plastic shear strain $\varepsilon_{c i}{ }^{p}$ which has been assumed $5 \%$ of the peak value, $\sigma_{\mathrm{ti}}$ is tensile strength of the bedding planes $\phi_{\mathrm{pj}}$ is the peak friction angle of the bedding planes simultaneously mobilised with the peak cohesion, $\mathrm{c}_{\mathrm{pi}}$; and $\mathrm{c}_{\mathrm{rj}}$ is the residual cohesion of the bedding planes at a plastic shear strain $\varepsilon_{c j}{ }^{p}$ which has been assumed $10 \%$ of the peak value. Figures 2 and 3 present the results of the hypothetical triaxial tests for confining pressures equal to zero and $1 \mathrm{MPa}$ respectively. The stress-strain curves clearly indicate the effect of varying the joint dip angle and consequently the plane of transverse isotropy on both rock mass sample strength and stiffness. In addition, the onset of unstable cracking or start of mobilisation of the frictional strength component is clearly observed by a kink in the stress-strain curve of those samples where failure occurs entirely within the rock matrix, i.e. samples with joint dip angle of $0^{\circ}, 30^{\circ}$ and $90^{\circ}$.

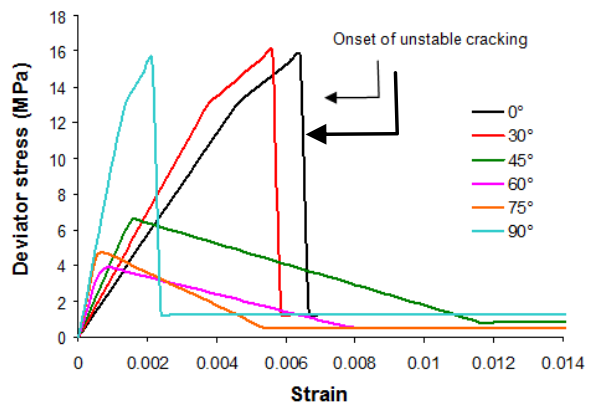

Figure 2 - Stress-strain curves for virtual samples tested at $\sigma_{3}=0 \mathrm{MPa}$ and varying joint angle

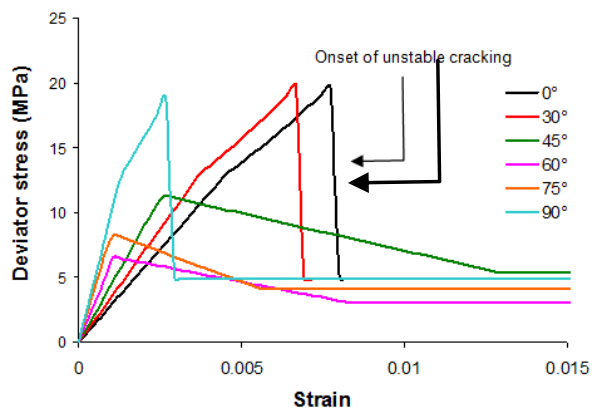

Figure 3 - Stress-strain curves for virtual samples tested at $\sigma_{3}=1 \mathrm{MPa}$ with varying joint angle

Figure $4 \mathrm{a}$ presents the axial stress developed upon axial loading at total axial strain of $0.08 \%$ for the rock mass samples under zero confining pressure. The results clearly indicate the effect of the 
transverse isotropy with increasing stiffness for increasing joint angle. The dotted lines indicate the values that would be observed if a fully isotropic model had been adopted with either $E_{1}$ (upper limit) and $E_{3}$ (lower limit), i.e. the results would be constant and independent of the joint angle. Figure $4 \mathrm{~b}$ presents values of peak axial stress and typical analytical U-shape strength curve with matching results of the ESUBI model.

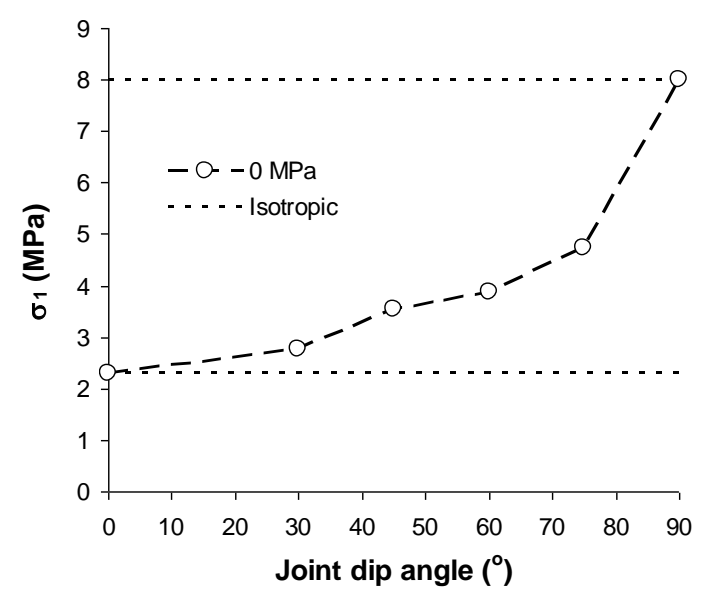

(a)

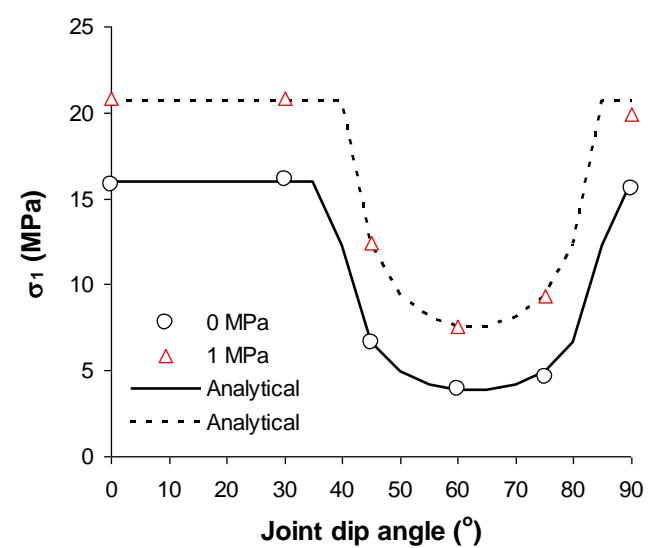

(b)

Figure 4 - (a) Stress mobilised at an axial strain of $0.08 \%$; (b) Peak axial stress

\section{EFFECT OF CWFS BEHAVIOUR AND TRANSVERSE ISOTROPY ON ROOF/FLOOR SOFTENING}

A simple hypothetical 2D model of a $5 \mathrm{~m}$ wide by $3 \mathrm{~m}$ high roadway excavation is presented in order to illustrate the potential effects of the both transverse isotropy and the non-simultaneous mobilisation of the cohesion and friction strength components, i.e. a CWFS approach, on the development of the excavation disturbed zone, i.e. the softening/fracturing zone in the roof/floor.

The roadway to be excavated was under a high initial horizontal stress of $12 \mathrm{MPa}$ and a vertical stress of $5 \mathrm{MPa}$. The following simplifying assumptions were made for both clarity of the results and to highlight the main potential differences in the modelling approaches:

- A homogenous rock mass represented by the parameters given in Table 1 was adopted both above and below a $3 \mathrm{~m}$ thick coal seam;

- Despite the ESUBI model capability of accounting for several joint sets only bedding planes are modelled;

- The coal seam was modelled assuming the parameters given in Table 2. For the coal, simultaneous mobilisation of friction and cohesion has been assumed;

- Excavation was assumed instantaneous which does not represent the more realistic gradual excavation of roadway development;

- No roof support was installed.

Table 2 - Coal parameters adopted

\begin{tabular}{|c|c|c|c|c|c|c|c|c|c|c|c|c|c|}
\hline \multicolumn{1}{|c|}{ Rock mass } & \multicolumn{10}{|c|}{ Intact rock } & \multicolumn{6}{c|}{ Bedding } \\
\hline $\begin{array}{c}E_{1} \\
(\mathrm{GPa})\end{array}$ & $\begin{array}{c}E_{3} \\
(\mathrm{GPa})\end{array}$ & $\begin{array}{c}\sigma_{\mathrm{ci}} \\
(\mathrm{MPa})\end{array}$ & $\begin{array}{c}\sigma_{\mathrm{ti}} \\
(\mathrm{MPa})\end{array}$ & $\begin{array}{c}\phi_{\mathrm{mp}} \\
\left({ }^{\circ}\right)\end{array}$ & $\begin{array}{c}\mathrm{C}_{\mathrm{pi}} \\
(\mathrm{MPa})\end{array}$ & $\begin{array}{c}\mathrm{C}_{\mathrm{ri}} \\
(\mathrm{MPa})\end{array}$ & $\begin{array}{c}\varepsilon_{\mathrm{ci}}{ }^{\circ} \\
(\%)\end{array}$ & $\begin{array}{c}\varepsilon_{f i}{ }^{p} \\
(\%)\end{array}$ & $\begin{array}{c}\phi_{\mathrm{pj}} \\
\left({ }^{\circ}\right)\end{array}$ & $\begin{array}{c}\mathrm{C}_{\mathrm{pj}} \\
(\mathrm{MPa})\end{array}$ & $\begin{array}{c}\mathrm{C}_{\mathrm{rj}} \\
(\mathrm{MPa})\end{array}$ & $\begin{array}{c}\sigma_{\mathrm{tj}} \\
(\mathrm{MPa})\end{array}$ & $\begin{array}{c}\varepsilon_{c j}{ }^{p} \\
(\%)\end{array}$ \\
\hline 5 & 1.43 & 10 & 0.1 & 30 & 3 & 0.3 & 1.6 & 0 & 30 & 0.5 & 0.1 & 0.1 & 1.2 \\
\hline
\end{tabular}

The following cases were investigated:

- Case 1 - An isotropic model was adopted for both coal and surrounding rock mass with $E_{1}$ assigned. Simultaneous mobilisation of cohesion and friction was assumed for both rock types; 
- Case 2 - A transverse isotropic model was adopted for both coal and surrounding rock mass with both $E_{1}$ and $E_{3}$ assigned. Simultaneous mobilisation of cohesion and friction is assumed for both rock types;

- Case 3 - An isotropic model was adopted for both coal and surrounding rock mass with $E_{1}$ assigned. A CWFS approach is adopted to model brittle behaviour;

- Case 4 - A transverse isotropic model was adopted for both coal and surrounding rock mass with both $E_{1}$ and $E_{3}$ assigned. A CWFS approach was adopted to model brittle behaviour.

\section{Model results}

Figures 5 to 12 present the results of the four cases investigated. These figures present both the failure modes experienced in the models as well as the pattern of total displacements.

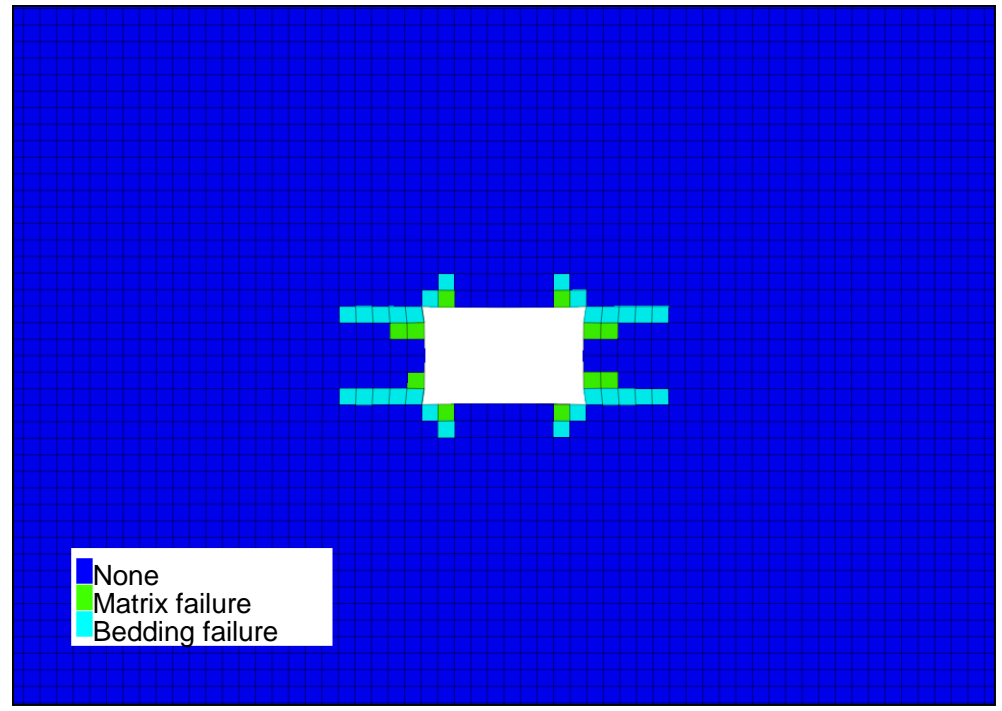

Figure 5 - Failure modes observed in Case 1 (exaggerated 15x)

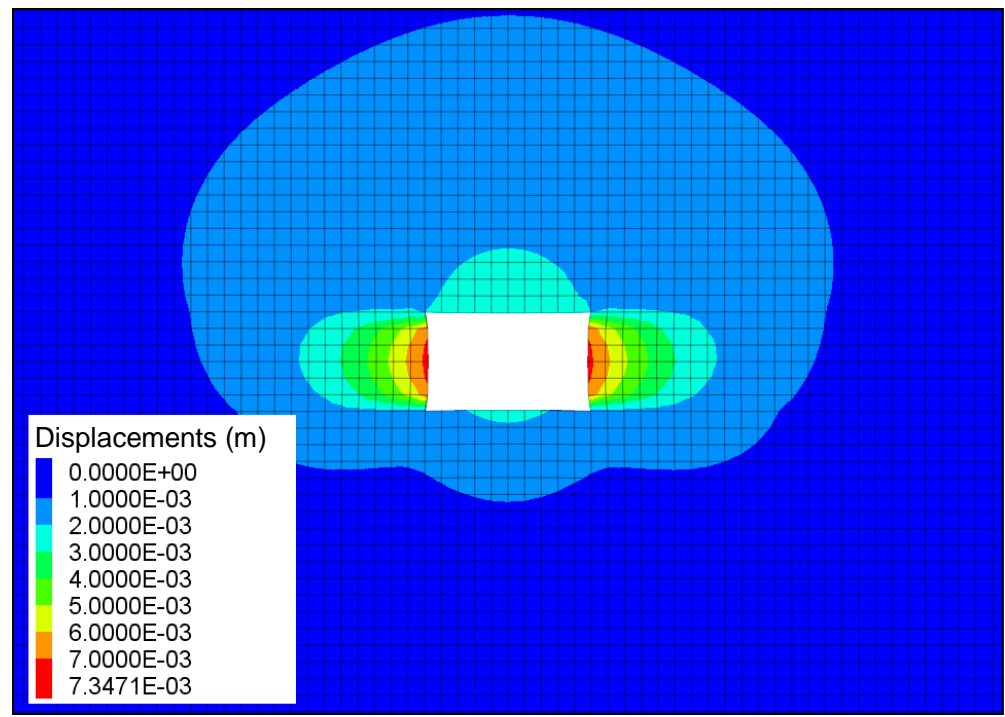

Figure 6 - Total displacements observed in Case 1 (exaggerated 15x) 


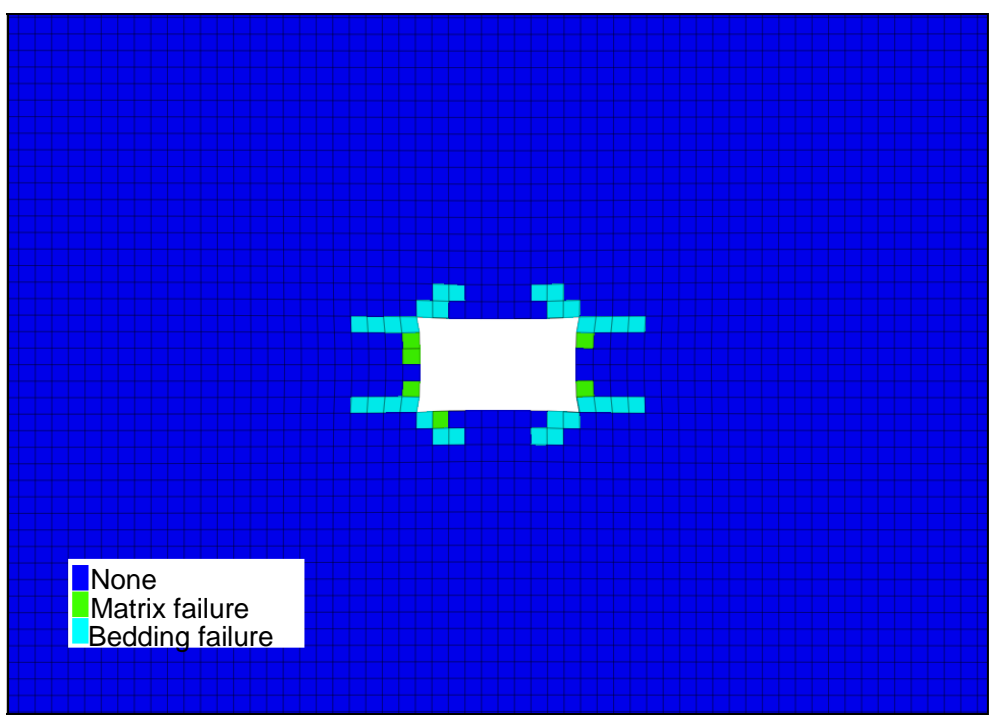

Figure 7 - Failure modes observed in Case 2 (exaggerated 15x)

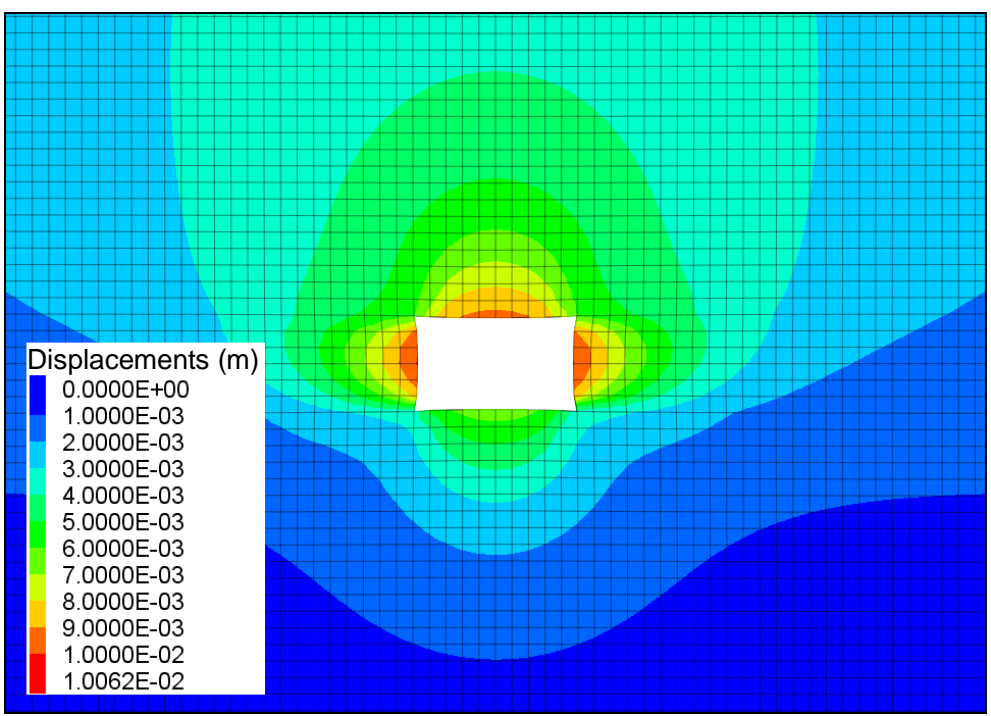

Figure 8 - Total displacements observed in Case 2 (exaggerated 15x)

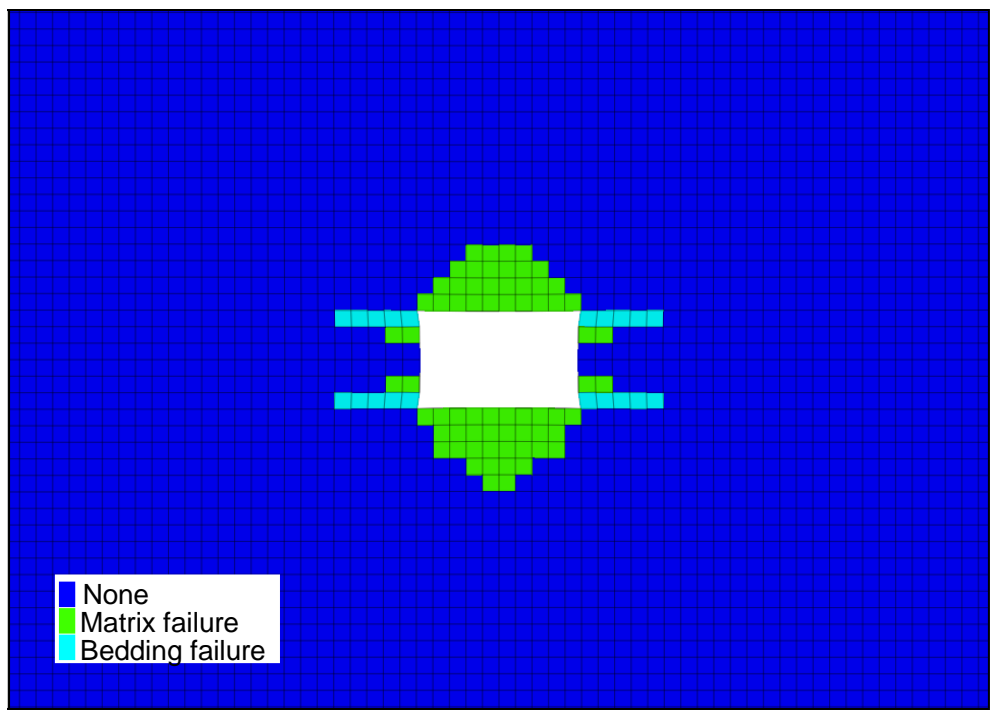

Figure 9 - Failure modes observed in Case 3 (exaggerated 15x) 


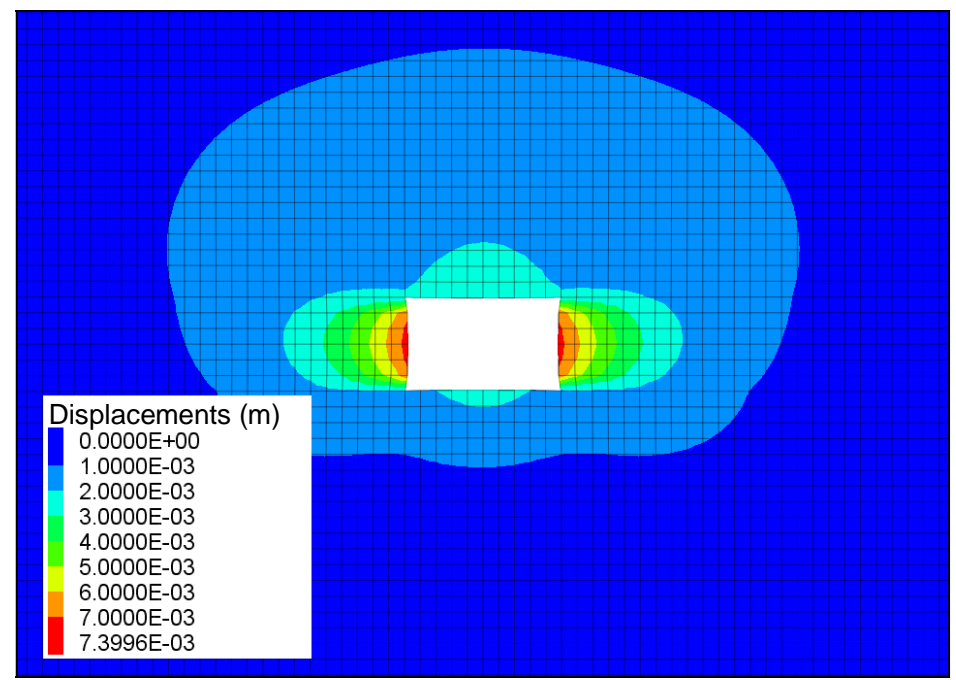

Figure 10 - Total displacements observed in Case 3 (exaggerated 15x)

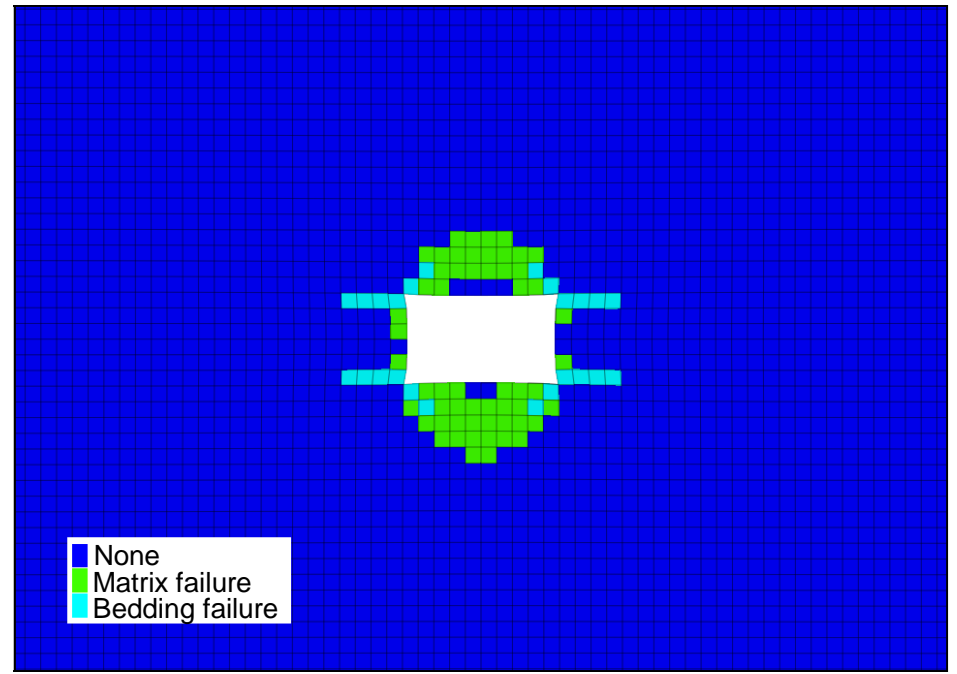

Figure 11 - Failure modes observed in Case 4 (exaggerated 15x)

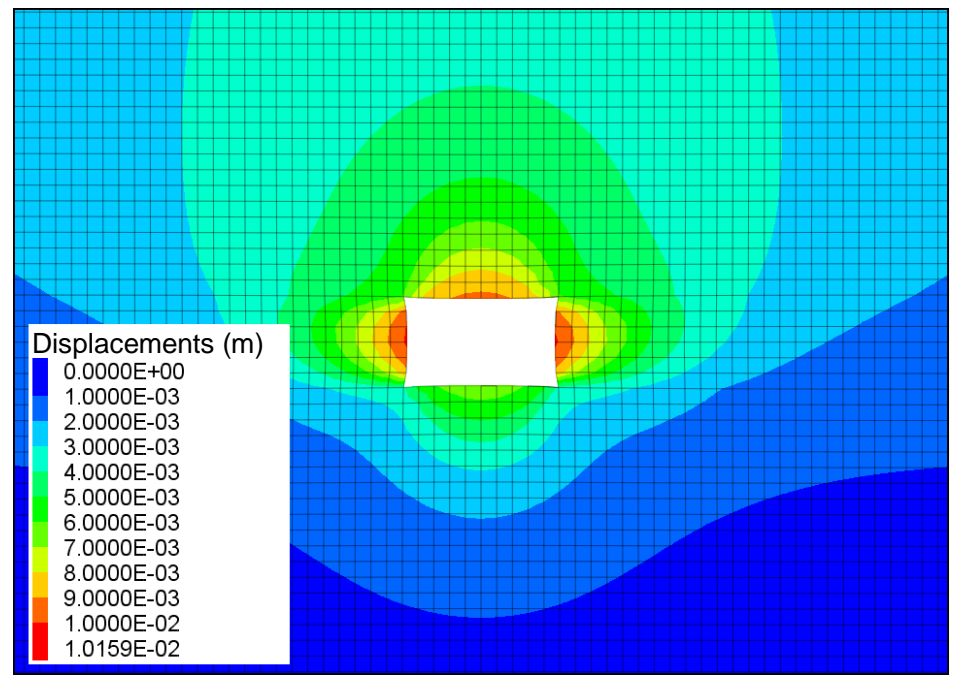

Figure 12 - Total displacements observed in Case 4 (exaggerated 15x)

The two cases with isotropic models (i.e. 1 and 3) showed very similar pattern and magnitude of displacements. When compared to the transverse isotropic models it becomes evident that those models will either under estimate or overestimate the displacements depending on the modulus adopted. 
In this case, as the higher modulus was adopted, both vertical and horizontal displacements were underestimated. The main difference between Case 1 and Case 3 is the extent and shape of the softened zone which is in agreement with the findings of (Hajiabdolmajid, et al., 2002). A simple brittle model with simultaneous mobilisation of strength parameters tends to underestimate the extent of the fractured zone. The CWFS approach indicates a deeper disturbed zone with a triangular shape that seems more realist when compared with those often observed in the field.

The two cases (i.e. 2 and 4) with transverse isotropy seem to provide a more realistic displacement pattern compatible with those often observed in the field, i.e. a deeper zone of influence, with a more linear decrease into the roof. Measurements of displacement near the excavation face are often used as an indication of the softened zone. However, only Case 4 with the CWFS approach indicated a fractured zone that seems more realistic than those experienced in the field. Case 2 mainly limited to bedding plane shearing, although with a similar displacement pattern.

\section{CONCLUSIONS}

An extended strain softening/hardening ubiquitous joint model has been developed to address some of the limitations of existing rock models, particularly with respect to transverse isotropy and the number of rock joint sets. The hypothetical triaxial test results presented above indicate that the model is capable of representing a range of failure modes capturing the effects of transverse isotropy which is often ignored in current roof support design.

When combining the model with a CWFS approach, a better modelling of brittle behaviour, e.g. fracturing/spalling, is observed. As a result, the shape and extent of the failed roof is also better modelled, not only with respect to displacements.

Results of the hypothetical and simple roadway model indicate that only displacement profiles in the roof may not fully represent the extent of the softened zone which may have a significant impact in the design of the roof support. For example, a deeper fractured zones may required longer tensile member (e.g. cable bolts) for suspension of the failed roof mass, which may not be captured when using a conventional brittle model.

It is important to note that the above investigation is a hypothetical case study with significant simplifications that do not fully represent roadway development in coal mines. A detailed geotechnical characterisation of the strata and stress field is required before applying in real cases. However, the hypothetical example illustrates the main differences that may be expected for the different modelling approaches and the potential shortcomings of current design approaches.

\section{REFERENCES}

Gale, W J, Fabjanczyk, M W, Tarrant, G C and Guy, R J, 1992. Optimization of reinforcement design of coal mine roadways. Proceedings, 11th International Conference on Ground Control in Mining, Wollongong, NSW, Australia, pp 272-279.

Gale, W J and Tarrant, G C, 1997. Let the rocks tell us. Proceedings, Symposium on Safety in Mines, The Role of Geology, Nov. 24-25, Newcastle, pp 153-160.

Hajiabdolmajid V, Kaiser P K, Martin C D, 2002. Modelling brittle failure of rock. Int J Rock Mech Min Sci, 39(6), pp 731-741.

Kelly, M, Gale, W J, Luo, X., Hatherly, P, Balusu, R. and LeBlanc, G, 1998. Longwall caving process in different geological environments better understanding through the combination of modern Assessment Methods. Proceedings, International Conference on Geomechanics/Ground Control in Mining and Underground Construction, July 14-17, Wollongong NSW Australia, Vol. 2, pp 573-589.

Mark, C, Dolinar, D R and Mucho, T P, 2000. Summary of field measurements of roof bolt performance. New Technology for Coal Mine Roof Support, Proceedings, NIOSH Open Industry Briefing, NIOSH IC 9453, pp 81-98.

Sandford, J, 1998. Review of longwall mining experience at South Bulga colliery. Proceedings, International Conference on Geomechanics/Ground Control in Mining and Underground Construction, July 14-17, Wollongong NSW Australia, Vol. 2, pp 591-597.

Seedsman, Ross, 2011. Application of the Brittle Failure Criterion to the Design of Roof Support in the Soft Rocks of Coal Mines. In Proceedings of $11^{\text {th }}$ Underground Coal Operators' Conference (Eds. Aziz N, Kininmonth B, Nemcik J and Ren T). 10-11 February, Wollongong, pp 60-72. http://ro.uow.edu.au/coal/342. 